\title{
A RESPONSABILIDADE CIVIL QUANTO AO DANO AMBIENTAL POR ÁGUA DE LASTRO
}

\author{
Caroline Barbosa Contente Nogueira ${ }^{1}$ \\ Universidade Federal do Amazonas (UFAM) \\ Cyntia Costa de Lima ${ }^{2}$ \\ Faculdade Martha Falcão | Wyden
}

Roger Luiz Paz de Almeida ${ }^{3}$

Universidade Federal do Amazonas (UFAM)

\section{RESUMO}

Este trabalho tem como foco o dano ambiental por águas de lastro, visando compreender a aplicação da responsabilidade civil ambiental nesse tema, observando a complexidade da circulação de bens e de serviços no sistema econômico hegemônico com o potencial de lesão à natureza. Pode-se inferir que a água de lastro é aquela utilizada pelos navios de carga, para equilíbrio e a segurança durante a navegação e que, quando despejada sem a perícia e o cuidado necessários, gera danos ambientais e econômicos irreversíveis. Para isso, foram utilizados os métodos dedutivo, descritivo e analítico, com abordagem qualitativa na realização da pesquisa bibliográfica e documental. As etapas consistiram em breve abordagem da proteção ambiental e sustentabilidade no Brasil, seguida da conceituação e da análise do conceito de dano ambiental e de responsabilidade civil ambiental, para, por fim, trabalhar o conceito de águas de lastro, bem como os possíveis danos e responsabilidade civil ambiental, exemplificando com casos

1 Doutora em Direito pela Pontifícia Universidade Católica do Paraná (PUC-PR), com estágio doutoral em Antropologia Jurídica (Doutorado Sanduíche/PDSE-CAPES) no Centro de Investigaciones y Estudios Superiores en Antropología Social (CIESAS). Mestra em Direito Ambiental pelo Programa de Pós-Graduação em Direito Ambiental da UFAM. Graduada em Direito pela Universidade do Estado do Amazonas (UEA). Professora do Programa de Pós-Graduação em Direito "Constitucionalismo e Direitos na Amazônia", da UFAM. Professora adjunta do Departamento de Direito Público da Faculdade de Direito da UFAM. ORCID: https://orcid.org/0000-0002-2282-3687 / e-mail: carolinenogueira@ufam.edu.br

2 Doutoranda em Direito DINTER-UFMG/UEA. Mestra em Direito Ambiental pela UEA. Professora do Curso de Direito da Faculdade Martha Falcão | Wyden. Membra da Comissão de Meio Ambiente - Ordem dos Advogados do Brasil, Seccional do Amazonas. Docente da Faculdade Martha Falcão | Wyden. Advogada. ORCID: https://orcid.org/0000-0003-4290-2208 / e-mail: cyntia.costa.lima@ gmail.com

3 Doutor em Direito pela PUC-PR, com estágio sanduíche na Universidade de Barcelona. Mestre em Direito Ambiental pela UEA. Magistrado vinculado ao Tribunal de Justiça do Amazonas (TJ/AM). Professor do Programa de Pós-Graduação em Direito "Constitucionalismo e Direitos na Amazônia" da UFAM. ORCID: https://orcid.org/0000-0001-6711-8618 / e-mail: roger.almeida@tjam.jus.br 
citados ao longo do trabalho. Isto posto, foi possível concluir que os danos ambientais causados pelo deslastre Brasil são de responsabilização civil ambiental de seus agentes, e, solidariamente do Estado, quando comprovada a negligência no gerenciamento e controle do deslastre.

Palavras-chave: água de lastro; dano ambiental; Direito Ambiental; responsabilidade civil ambiental.

\title{
CIVIL RESPONSIBILITY FOR ENVIRONMENTAL DAMAGE $B Y B A L L A S T$ WATER
}

\begin{abstract}
This paper focuses on the environmental damage caused by ballast water, and the objective is to understand the application of environmental liability in this theme, observing the complexity of the circulation of assets and services in the hegemonic economic system with the potential for injury to nature. It can be inferred that ballast water is used by cargo ships for balance and safety during navigation, and, when discharged without the necessary skill and care, generates irreversible environmental and economic damage. To this end, a deductive, descriptive and analytical method was used, with a qualitative approach in the bibliographical and documentary research. The steps are consisted of a brief approach to environmental protection and sustainability in Brazil, followed by the conceptualization and analysis of the concept of environmental damage and environmental liability, to finally work on the concept of ballast water, as well as the possible damages and risks, exemplifying with cases cited throughout the work. Therefore, it was possible to conclude that the environmental damage caused by Brazil is environmental liability of its agents, and joint liability of the State, when proven negligence in the management and control of these disasters.
\end{abstract}

Keywords: civil liability for the environment; environmental damage; Environmental Law; waters ballast. 


\section{INTRODUÇÃO}

Os danos ambientais causados por água de lastro são diversos e com diferentes tipos de impacto ambiental e, por esse motivo, o presente artigo científico tem o objetivo de realizar uma pesquisa bibliográfica consubstanciada teoricamente em teses, dissertações, monografias, trabalhos de conclusão de curso, artigos científicos e em legislações internacionais e nacionais, tomando como base normativa a Constituição Brasileira de 1988. Isto para fazer uma análise qualitativa da responsabilidade civil ambiental quanto ao dano ambiental causado por imperícia e negligência no trato da água de lastro, no que tange à jurisdição do Estado brasileiro.

Segundo a Norma da Autoridade Marítima para o Gerenciamento de Água de Lastro de Navios (NORMAM-20/DPC), água de lastro é aquela levada a bordo de um navio para o controle do trim, banda, calado, estabilidade ou tensões do navio, e possuem partículas suspensas (BRASIL, 2005).

O lastreamento ocorre no momento em que se despeja essa água nos portos onde os navios são atracados, trazendo o risco de contaminação em vista do potencial nocivo e tóxico que são carregados dentro dos tanques de reserva dessa água de lastro, visto que podem conter partículas ou microrganismos nocivos e exóticos, que podem causar desequilíbrio ao bioma local.

No entanto, apesar do risco que envolve o transporte de água de lastro, sabe-se que é fundamental para garantia da segurança e da eficiência das navegações, pois que mantém a estabilidade, o balanço e a integridade estrutural do navio. Por esse motivo, cabe ao direito ambiental analisar a questão dos danos ambientais e a responsabilidade civil, bem como, promover a prevenção de danos ambientais comprovados por estudos científicos de estudos e monitoramento de espécies exóticas que comprovam a mudança na condição aquática da região invadida, podendo levar à extinção de espécies nativas, além de prejuízos para economia local, chamada pelos cientistas de bioinvasão.

Por esse motivo, o trabalho se propõe a estudar a responsabilidade civil ambiental por dano ambiental advindo do lastreamento das águas trazidas nos navios, causando a bioinvasão. Para atingir o objetivo desta pesquisa, serão analisadas as legislações e estudos teóricos sobre direito ambiental brasileiro e internacional, no que diz respeito ao dano ambiental, à tutela da água e da biodiversidade aquática. 
No primeiro momento desta pesquisa, será feito um levantamento bibliográfico da legislação e da teoria acerca da proteção ambiental no Brasil, especificamente sobre tutela das águas e da biodiversidade aquática brasileira, para em seguida debruçar-se sobre o conceito de água de lastro e os danos ambientais em potencial.

Na sequência deste estudo, será estudada a responsabilidade civil, a partir da perspectiva geral, para compreender o que é responsabilidade civil ambiental no Direito brasileiro, para em seguida, estudar o dano ambiental.

Como síntese desta análise, será abordada a responsabilidade civil por dano causado por água de lastro, compreendendo a viabilidade de tal responsabilização e suas características, assim como, analisando criticamente a legislação brasileira acerca do tema, para averiguar se há uma proteção específica e pertinente dentro do país, assim como, as normas internacionais que podem ser invocadas para responsabilização de tal dano, quando ratificadas pelo Brasil.

Desta feita, pretende-se compreender também, a efetividade dessas normas, entendendo que a mera legislação positivada não é o suficiente para dar conta do dano ambiental, e, entendendo também a grande relevância do tema para questões não somente ambientais, mas para sadia qualidade de vida e sobrevivência e reprodução da biodiversidade atingida por água de lastro e pelas implicações econômicas quando da nocividade da perda de espécies nativas que compõem a economia local.

\section{A PROTEÇÃO AMBIENTAL BRASILEIRA}

\subsection{O Direito Ambiental e a sustentabilidade}

A proteção do meio ambiente é essencial à sobrevivência da humanidade, por esse motivo, é pauta das políticas internacionais que se voltam à crise ambiental e socioambiental que vive a sociedade moderna.

A crise ambiental que se instala mundialmente deve ser vista de modo holístico, denotando-se não só a questão ambiental, mas também a interferência do modo de produção, ou seja, da economia, sobre o meio ambiente e a vida social (LEFF, 2002).

O que se denomina crise ambiental é uma série de fatores que implicam a utilização indiscriminada de recursos naturais, sem possibilidade de renovação própria da natureza. Isso implicou, principalmente a partir da 
década de 70, em teses científicas que demonstraram o aumento do buraco da camada de ozônio, seguidas de outras teses que comprovaram a crise energética, hídrica, de resíduos sólidos, poluição e climática.

Entretanto, antes desses alarmes da ciência, os economistas não tinham a preocupação com meio ambiente e desenvolvimento sustentável, visto que se esperava que a tecnologia superasse todas as dificuldades humanas, mas o que se percebeu foi uma grande crise ambiental que atingiu um alto grau de tensão, representando um desafio enorme à sobrevivência da humanidade (MIKHAILOVA, 2004).

A alternativa encontrada nos diálogos internacionais foi a do desenvolvimento sustentável. Esse conceito foi delineado desde a Conferência de Estocolmo, em 1972, na Suécia, que representa um marco para as discussões ambientais. A conferência de Estocolmo buscou um equilíbrio entre desenvolvimento econômico e redução da degradação ambiental, que mais tarde se desenvolveria no conceito de desenvolvimento sustentável (MACHADO, 2017; ANTUNES, 2010; MILARÉ, 2013).

Foi a Primeira Conferência mundial sobre o Homem e o Meio Ambiente, que resultou na Declaração sobre Ambiente Humano ou Declaração de Estocolmo, que rompeu com o paradigma de que os recursos naturais eram inesgotáveis, demonstrando que o avanço desenfreado e o consumo incoerente acarretam consequências drásticas ao meio ambiente, como o secamente de rios, lagos, ilhas de calor, efeito estufa e inversão térmica (MACHADO, 2017; ANTUNES, 2010; MILARÉ, 2013).

A Organização das Nações Unidas (ONU) seguiu com os debates sobre a questão ambiental com a Comissão Mundial sobre Meio Ambiente e Desenvolvimento, criada pela ONU com a função de discutir e propor formas de harmonizar os objetivos básicos da sustentabilidade, quais sejam: o desenvolvimento econômico e a conservação ambiental (MACHADO, 2017; ANTUNES, 2010; MILARÉ, 2013).

Mamed e Duarte (2012, p. 5294) retomam os conceitos discutidos pela referida comissão da seguinte maneira:

O conceito de desenvolvimento sustentável ganhou uma dimensão global através do Relatório Brundtland, de 1987 da Comissão Mundial sobre o Meio Ambiente e Desenvolvimento. Esse Relatório, conhecido como "Nosso Futuro Comum" determinou que da expressão "desenvolvimento sustentável" depreende-se que a fruição dos recursos naturais pela presente geração, não deve prejudicar o mesmo direito das gerações futuras. 
Portanto, percebe-se que as reuniões de Estocolmo (1972) e Rio (1992) trouxeram a noção de desenvolvimento baseado nos limites dos recursos naturais e no desenvolvimento social. A importância de proteção ambiental para garantia da vida e desenvolvimento das gerações futuras também é fato relevante para a sustentabilidade, já que esta busca um equilíbrio entre as ações humanas sobre o meio ambiente e a capacidade de resiliência deste último.

O referido Relatório Brundtland (1987), que abriu o debate para a academia sobre o conceito de sustentabilidade ou desenvolvimento sustentável, tinha objetivo de propor justamente o questionamento sobre a aplicabilidade desse conceito. Em suas origens,

A ideia de sustentabilidade ganha corpo e expressão política na adjetivação do termo desenvolvimento, fruto da percepção de uma crise ambiental global. Essa percepção percorreu um longo caminho até a estruturação atual, cujas origens mais recentes estão plantadas na década de 1950, quando pela primeira vez a humanidade percebe a existência de um risco ambiental global: a poluição nuclear. Os seus indícios alertaram os seres humanos de que estamos em uma nave comum, e que problemas ambientais não estão restritos a territórios limitados (NASCIMENTO, 2012, p. 52).

A degradação ambiental passa a ser pauta para a agenda dos países desenvolvidos e em desenvolvimento, visto que, para os primeiros afeta sobremaneira sua qualidade de vida, já os segundos, não querem restrição à exportação de seus produtos primários, ou seja, afeta diretamente em sua economia (MAMED; DUARTE, 2012).

Assim, o Relatório Brundtland abriu os debates para o conceito de desenvolvimento sustentável, entendendo que o desenvolvimento deveria satisfazer as necessidades presentes, sem comprometer a capacidade das gerações futuras de suprir suas necessidades (BRUNDTLAND, 1987).

Iniciativas foram tomadas em nível mundial, até que a Conferência da Eco-92, ocorrida no Rio de Janeiro, veio estabelecer a Agenda 21, que estabeleceu a importância do compromisso de cada país em propor reflexões em escala local e global para gerenciar as atividades públicas e de iniciativa privada, no sentido de alcançar o desenvolvimento sustentável.

O paradigma do progresso foi reinterpretado, buscando contemplar harmonia e equilíbrio holístico entre todas as partes, promovendo não somente crescimento quantitativo econômico, mas também, crescimento qualitativo no índice de desenvolvimento humano (IDH) (BRASIL, 2004).

As iniciativas demandavam inclusão social e mitigação dos conflitos socioambientais decorrentes da concentração do acesso aos recursos 
naturais e da exploração desmedida da natureza. Isso inclui um planejamento participativo por parte de cada país para inclusão social, no que se refere à educação, saúde e distribuição de renda, sustentabilidade urbana e rural, em busca da preservação dos recursos naturais e minerais, que só seriam alcançados através da ética política visando o desenvolvimento sustentável (BRASIL, 2004).

$\mathrm{E}$, nesse contexto, o direito ambiental internacional vai se moldando e estabelecendo pactos importantes para direcionar os compromissos estatais com a sustentabilidade que visa a proteção do meio ambiente para uma sadia qualidade de vida, não somente para essas gerações, como para as gerações futuras.

\subsection{O Direito Ambiental e a Tutela Jurídica Brasileira do Meio Ambiente}

A legislação ambiental é necessária em nosso sistema econômico porque o limita frente à exploração dos recursos naturais. Além da Constituição Brasileira de 1988 tratar do meio ambiente em um capítulo especial, o Brasil possui um sistema jurídico para proteção ambiental considerados dos mais avançados em comparação a outros países no mundo.

Entre as principais normas que objetivam a proteção do meio ambiente estão: Lei n. 6.938/81, Política Nacional do Meio Ambiente; Lei n. 9.433/97, Política Nacional de Recursos Hídricos; Lei n. 9.759/99, Política Nacional de Educação Ambiental; Lei n. 9.985/00, Sistema Nacional de Unidades de Conservação da Natureza; Lei n. 12.305/10, Política Nacional de Resíduos Sólidos; Lei n. 12.651/12, Novo Código Florestal; entre outras.

O termo Meio ambiente é definido pelo art. $3^{\circ}$, I, da Lei 6.938/1981, que estabelece a Política Nacional do Meio Ambiente - PNMA:

Art. $3^{\circ}$ - Para os fins previstos nesta Lei, entende-se por:

I - meio ambiente, o conjunto de condições, leis, influências e interações de ordem física, química e biológica, que permite, abriga e rege a vida em todas as suas formas (BRASIL, 1981).

Ainda comentando o supracitado artigo da PNMA, seu inc. II trata "degradação da qualidade ambiental como a alteração adversa das características do meio ambiente" e a poluição, no inc. III e alíneas, como a "degradação da qualidade ambiental resultante de atividades que direta 
ou indiretamente" tragam prejuízos à saúde, segurança e bem-estar das pessoas, criem "condições adversas às atividades sociais e econômicas", atinjam e interfiram "desfavoravelmente a biota", e, "lancem matérias ou energia em desacordo com os padrões ambientais estabelecidos” (BRASIL, 1981).

Para o caso deste estudo sobre os aspectos jurídicos dos danos ambientais causados por água de lastro, as alíneas $d$ e $e$ do inc. III do art. $3^{\circ}$ da PNMA caracterizam explicitamente a poluição que gerada pela atividade de descarregar águas estranhas no território brasileiro.

O Direito Ambiental, como matéria autônoma, é "ramo do direito público composto por princípios e regras que regulam direta ou indiretamente o meio ambiente", conforme as palavras de Amado (2014, p. 40) em quaisquer de suas dimensões.

E segue anunciando o mesmo autor, que direito ambiental no Brasil objetiva especialmente o controle da poluição, a fim de mantê-la dentro dos padrões toleráveis, "para instituir um desenvolvimento econômico sustentável, atendendo as necessidades das presentes gerações sem privar as futuras de sua dignidade ambiental" (AMADO, 2014, p. 40).

Nessa esteira, segue o direito ambiental a interpretação de que onde houver dúvida, o meio ambiente deve ser favorecido (in dubio pro ambiente), conforme apontam Morato Leite e Belchior (2009).

Os fundamentos do direito ambiental contam também com princípios que são normas jurídicas fundamentais de um sistema jurídico, carregam consigo características como a abstração e a generalidade, o que o torna indeterminado quando comparados com regras objetivas que regulam situações fáticas. Os princípios, portanto, trazem consigo mandamentos subjetivos, aplicáveis a diversas situações jurídicas, devendo chamar a interpretação dos juristas, juntamente com as regras positivadas objetivas, os precedentes judiciais, os costumes e regras sociais, a teoria jurídica ou doutrina, entre outras fontes do direito (ALEXY, 2008).

Dentre os princípios do Direito ambiental, serão mencionados os mais importantes para o estudo deste trabalho, como o princípio do desenvolvimento sustentável, da prevenção, da precaução, da responsabilidade ou do poluidor-pagador e o princípio do meio ambiente ecologicamente equilibrado como direito fundamental da pessoa humana.

O princípio do desenvolvimento sustentável, como já tratado neste trabalho, é oriundo da Conferência de Estocolmo, de 1972, e, configura como aquele primordial para o Direito Ambiental. Busca o crescimento 
econômico, a preservação ambiental e a equidade social. Por esse princípio, a erradicação da pobreza, com redistribuição equitativa de renda e acesso equitativo aos recursos naturais passam a ser equilibrados com o crescimento econômico e a proteção do meio ambiente (SILVA, 2015).

A Constituição Federal Brasileira de 1988 relaciona o desenvolvimento sustentável em seu art. 170, que determina a ordem econômica do país, observando os princípios como o da função social da propriedade, da livre concorrência, da defesa do consumidor, da defesa do meio ambiente, da redução da desigualdade social, entre outros (BRASIL, 1988).

Por sua vez, o princípio do meio ambiente ecologicamente equilibrado como direito fundamental da pessoa humana, oriundo também da Declaração de Estocolmo das Nações Unidas sobre o Meio Ambiente, de 1972, que determina:

O homem tem o direito fundamental à liberdade, à igualdade, e ao desfrute de adequadas condições de vida em um meio cuja qualidade lhe permita levar uma vida digna e gozar de bem-estar e tem a solene obrigação de proteger e melhorar esse meio para as gerações presentes e futuras (ONU, 1972).

A Constituição Federal Brasileira de 1988 recepcionou esse princípio em seu art. 225, que reza: "todos têm direito ao meio ambiente ecologicamente equilibrado, bem de uso comum do povo e essencial à sadia qualidade de vida [...]" (BRASIL, 1988).

Diante da proteção internacional e interna, pode-se inferir que o direito ao meio ambiente ecologicamente equilibrado é intimamente ligado com a dignidade da pessoa humana e, portanto, é dever do Estado garantir tais princípios fundamentais de sua existência, sobretudo, quando se trata de meio ambiente, proteger para que a qualidade de vida seja atingida (SILVA; 2015).

O Princípio da Prevenção é consagrado no art. 225 da Constituição Federal Brasileira de 1988 e se observa também nas resoluções do Conselho Nacional de Meio Ambiente - CONAMA. Esse princípio reconhece que há "base científica para prever os danos ambientais decorrentes de determinada atividade lesiva ao meio ambiente, devendo-se impor ao empreendedor condicionantes ao licenciamento ambiental para mitigar ou elidir os prejuízos" (AMADO, 2014).

Tal princípio determina que diante do conhecimento científico que a humanidade detém hodiernamente, é possível mensurar risco certo, conhecido ou concreto diante dos empreendimentos realizados frente 
à natureza. Por esse princípio também fica determinada importância de prevenir danos ambientais possivelmente irremediáveis usando a certeza científica (AMADO, 2014).

O princípio da prevenção é o alicerce do Estudo de Impacto Ambiental EIA, previsto no art. 225, $\S 1^{\circ}$, IV, da Constituição Federal Brasileira de 1988, que "deve ser realizado pelos interessados antes de iniciada a atividade potencialmente degradadora do meio ambiente, dentre outras medidas preventivas a serem exigidas pelos órgãos públicos" (SILVA, 2015, p. 67).

O princípio da precaução vem do direito alemão e tem previsão explícita na Constituição Federal Brasileira de 1988, em seu art. 225. É visto também na Declaração do Rio (ECO/92), no Princípio 15, que estabelece:

De modo a proteger o meio ambiente, o princípio da precaução deve ser amplamente observado pelos Estados, de acordo com suas capacidades. Quando houver ameaça de danos sérios ou irreversíveis, a ausência de absoluta certeza científica não se deve ser utilizada como razão para postergar medidas eficazes e economicamente viáveis para precaver a degradação ambiental.

A Declaração não tem natureza jurídica de Tratado Internacional, funciona como compromisso adotados pelos países. Machado (2017, p. 103) afirma que o princípio da precaução "consiste em dizer que não somente somos responsáveis sobre o que nós sabemos, sobre o que nós deveríamos ter sabido, mas, também, sobre o que nós deveríamos duvidar".

Esse princípio remonta novamente o in dubio pro natura ou salute, caracterizando a antecipação do risco que o empreendimento pode oferecer de degradação ambiental, conforme explica Machado (2017, p. 111) "na dúvida, opta-se pela solução que proteja imediatamente o ser humano e conserve o meio ambiente", e continua esclarecendo

[...] em certos casos, em face da incerteza científica, a relação de causalidade é presumida com o objetivo de evitar a ocorrência de dano. Então, uma aplicação estrita do princípio da precaução inverte o ônus normal da prova e impõe ao autor potencial provar, com anterioridade, que sua ação não causará danos ao meio ambiente (MACHADO, 2017, p. 113).

Esse riso é, portanto, abstrato ou potencial. Com base nesse princípio ocorre a inversão do ônus da prova nas demandas ambientais, "carregando ao réu (suposto poluidor) a obrigação de provar que a sua atividade não é perigosa nem poluidora, em que pese inexistir regra expressa nesse sentido". Destarte, essa tese foi recepcionada pelo Superior Tribunal de Justiça, em 20094 (AMADO, 2014).

4 Resp 972.902-RS, Rel. Min. Eliana Calmon, j. 25.08.2009. 
Segundo Silva (2015, p. 69), o princípio da precaução traz a ética do cuidado, que "não se satisfaz apenas com a ausência de certeza dos malefícios, mas privilegia a conduta humana que menos agrida, ainda que eventualmente, o meio natural".

O último princípio a ser mencionado, lembrando que a doutrina traz outros de também importância para o Direito Ambiental, é o princípio do Poluidor-Pagador, "considerado fundamental na política ambiental, pode ser entendido como um instrumento econômico que exige do poluidor, uma vez identificado, suportar as despesas da prevenção, reparação e repressão dos danos ambientais" (SILVA, 2015, p. 73).

Esse princípio advém da noção que os empreendimentos aplicados frente ao meio ambiente, que possam causar ou que causem danos, devem ser reparados e prevenidos. Derani (2008, p. 142-143) aponta que:

\footnotetext{
Durante o processo produtivo, além do produto comercializado, são produzidas "externalidades negativas". São chamadas externalidades porque, embora resultantes da produção, são recebidas pela coletividade, ao contrário do lucro, que é percebido pelo produtor privado. Daí a expressão "privatização dos lucros e socialização de perdas", quando identificadas as externalidades negativas. Com a aplicação deste princípio procura-se corrigir este custo adicionado à sociedade, impondo-se sua internalização.
}

Há a necessidade de repassar ao produtor os custos das externalidades negativas, visto que os impactos ambientais afetam à sociedade como um todo. E, pelo fato de os bens ambientais serem finitos, limitados e bem comum de todos, como interesses difusos e coletivos, é aplicado o princípio do poluidor-pagador (SILVA, 2015).

Outra perspectiva sobre esse princípio é de Carneiro (2009, p. 69) que anota: "estes bens, os quais poderíamos classificar como bens escassos em termos absolutos, tais como o ar ou a água, por sua natureza, em princípio não entram no circuito econômico e nem se regem pelas relações criadas socialmente", estas criadas para enfrentar o problema da escassez.

Para equilibrar as externalidades negativas, a sociedade encontra no Estado o agente externo ao mercado que poderá, através de políticas públicas, mitigar os interesses os impactos gerados pelos econômicos, considerando os custos sociais da degradação ambiental. Tais políticas podem ser implementadas por "regulação direta do comportamento dos agentes econômicos e a adoção de incentivos e instrumentos de natureza econômica que induzem o poluidor a não degradar a natureza" (SILVA, 2015, p. 75). 
Dessa maneira, pode-se compreender que o Direito Ambiental, munido de princípios internacionais, constitucionais e regras objetivas positivas, complementa o ordenamento jurídico brasileiro de maneira a ser interpretado sistematicamente, para que, diante das mais diferentes demandas sociais e jurídicas, não ser deixado de lado, frente à relevância do meio ambiente ecologicamente equilibrado para garantia da qualidade da vida humana no planeta.

Diante da temática estudada, o potencial de impactos ambientais advindos da água de lastro necessita ser estudado em vista da relevância da água como bem finito e imprescindível à garantia da vida na Terra. Para isso, passa-se a estudar como o direito regulamenta a proteção da água e da biodiversidade aquática, a fim de compreender que medidas podem ser tomadas diante dos riscos ambientais iminentes.

\section{A RESPONSABILIDADE CIVIL E DANOS AMBIENTAIS}

Antes de nos aprofundarmos no tema de responsabilização, faz-se necessária a compreensão do conceito de dano ambiental, cuja base de estudo encontra-se presente na doutrina jurídica pátria, em vista da omissão constitucional sobre o tema.

Para Carvalho (2013, p. 103),

O dano ambiental consiste em uma noção que integra a lesão a interesses transidividuais e individuais, assim como suas repercussões atingem tanto o meio ambiente natural com os elementos ambientais antrópicos. Essa integração multifacetada fornece amplitude e grande complexidade ao sentido jurídico de dano ambiental, como corolário ao próprio direito à vida.

Do ponto de vista legal, a Política Nacional de Meio Ambiente PNMA também não se ocupa explicitamente do assunto em seu texto, no entanto, do art. $3^{\circ}$, II, que conceitua degradação ambiental como "a alteração adversa das características do meio ambiente" oferece a interpretação pelo dano ambiental. O inc. III da PNMA, por sua vez, define poluição, como já citado no item anterior, ratificando a degradação da qualidade ambiental.

Milaré (2011, p. 1119) entende dano ambiental como "a lesão aos recursos naturais, com consequente degradação - alteração adversa ou in pejus - do equilíbrio ecológico e da qualidade de vida". Com efeito, para os fins propostos para este trabalho, entende-se por dano ambiental a lesão causada aos recursos naturais disponíveis, capaz de afetar o bem-estar dos 
indivíduos que deles dependem para a fruição do direito à sadia e qualidade de vida.

A noção de dano ambiental se mostra imprescindível para a compreensão das nuances do sistema de responsabilização civil em matéria ambiental, posto as marcantes diferenças havidas entre aquele tipo de dano e sua forma tradicional. Enquanto este atinge uma determinada vítima ou a um conjunto individualizado de vítimas, já aquele, tem o potencial de atingir uma coletividade de vítimas, posto a possibilidade de materializar-se em dimensões jurídicas distintas, possibilitando uma classificação sob o critérios de interesses lesados (tanto na esfera individual quanto coletiva) e natureza do bem violado (de dano ambiental patrimonial ou extrapatrimonial) (CARVALHO, 2013, p.104). Com efeito, a lesão ambiental tem o potencial de afetar, a depender de sua magnitude, uma pluralidade difusa de vítimas.

Para levar a cabo a responsabilização do dano ambiental, desponta outra característica que dificulta ainda mais sua aplicação: sua configuração probatória em razão da complexidade do bem jurídico tutelado (ambiente), das incertezas científicas que marcam o diagnóstico de suas consequências e do potencial ofensivo das atividades de risco, bem como de suas verdadeiras causas (CARVALHO, 2013).

A prova científica do dano ambienta, essencial para estabelecer o nexo de causalidade entre a conduta do poluidor e a lesão, perpassa necessariamente pela interseção entre ciência e direito, que se materializa pela assimilação jurídica das informações técnicas a respeito das causas e consequências das irritações ecológicas. A interação entre esses ramos de conhecimento se complexifica a partir das limitações jurídicas em operar em uma clausura normativa, sendo ainda mais dificultada em razão dos efeitos colaterais do progresso técnico-científico.

O dano ambiental se apresenta em múltiplas formas, muitas vezes marcadas pela ausência de certeza quanto à reversibilidade de seus efeitos. É também caracterizado pela difícil reparação, impondo desafios à restauração ecológica à condição ou estado anterior ao dano. Milaré (2013, p. 326) adverte que "por mais custosa que seja a reparação, jamais se reconstituirá a integridade ambiental ou a qualidade do meio que for afetado".

Outro desafio que se impõe à responsabilização civil ambiental consiste na difícil aferição do dano, em razão da dificuldade em quantificar ou atribuir valores monetários ao meio ambiente, um dano cometido a um bioma pode levar tempo até atingir outros, em vista da característica natural de interconexão e sinergia da biodiversidade. 
Milaré (2013, p. 740) também ressalta que "mesmo levado avante o esforço reparatório, nem sempre é possível, no estágio atual do conhecimento, o cálculo da totalidade do dano ambiental". Destarte, há ainda a possibilidade de um dano continuar gerando prejuízos em cadeia, de maneira indireta e cumulativa.

A reparação do dano ambiental é estabelecida no art. $4^{\circ}$, VII, da PMNA, que impõe ao poluidor a obrigação de recuperar e/ou indenizar os danos causados. Segundo Machado (2017, p. 429), o "Direito Ambiental apresenta um novo tipo de comportamento ao efetivar-se a responsabilização jurídica do poluidor".

A responsabilização jurídica do agressor dos recursos ambientais traduz-se na aplicação dos princípios do poluidor-pagador e da reparação integral. O primeiro, já citado anteriormente, objetiva a internalização dos prejuízos causados pelo dano ambiental. O segundo, associa-se à ideia de compensação e "estabelece que o dano ao meio ambiente deve ser reparado integralmente, ou seja, de forma ilimitada vedando a utilização de fórmulas que, de alguma maneira, possa evitar que o meio ambiente seja integralmente recuperado e restaurado" (AUHAREK; ARAÚJO, 2009, p. 9).

Milaré (2011, p. 1.252) entende tal princípio da seguinte maneira:

O Brasil adotou a teoria da reparação integral do dano ambiental, o que significa que a lesão causada ao meio ambiente há de ser recuperada em sua integridade e qualquer norma jurídica que disponha em sentido contrário ou que pretenda limitar o montante indenizatório a um teto máximo será inconstitucional; por isso mesmo, quando não for possível a reparação do dano, ainda será devida a indenização pecuniária correspondente, a ser revertida para os Fundos de Defesa dos Direitos Difusos, previstos no artigo 13 da Lei 7.347/85

A Constituição Federal de 1988, em seu art. 225 , § $3^{\circ}$, e a PNMA, em seu art. $14, \S 1^{\circ}$, estabelecem tal princípio e, diante dele, há sempre o dever jurídico de reparação quando da degradação ambiental que afete o meio ambiente.

Quanto à responsabilidade civil, pode-se compreender como um instrumento jurídico que obriga um infrator a ressarcir um dano causado a outrem. Há a pressuposição de um prejuízo a terceiro que gera o dever de reparar, por isso, é necessário identificar a conduta geradora do dano e da obrigação de reparação.

O Princípio 13, da Declaração do Rio, afirma que: "Os Estados deverão desenvolver a legislação nacional relativa à responsabilidade e à indenização referente às vítimas de contaminação e outros danos ambientais. 
[...] (ONU, 1992). A Constituição Federal Brasileira de 1988, em seu art. $225, \S 3^{\circ}$, afirma a possibilidade de responsabilização ambiental às condutas lesivas ao meio ambiente, sujeitando os infratores, pessoas físicas ou jurídicas, a sanções penais e administrativas, independentemente da obrigação de reparar os danos causados.

O art. 927 do Código Civil trata da responsabilidade civil extracontratual, determinando que "aquele que, por ato ilícito, causar dano a outrem, fica obrigado a repará-1o" (BRASIL, 2002). A PNMA, em seu art. 4º, VII, determina a "imposição ao poluidor da obrigação de recuperar e/ou indenizar os danos causados" (BRASIL; 1981).

A responsabilidade civil pode ser classificada em objetiva e subjetiva. A subjetiva diz respeito à culpabilidade ou não do causador do dano, pois que, se não há culpa, não há reparação civil. Para analisar a responsabilização civil é necessário averiguar se houve negligência, imperícia ou imprudência, e, a partir disso, analisar o dever de ressarcimento à vítima. Para configurar responsabilidade civil subjetiva é imprescindível a presença dos elementos: conduta antijurídica, dano, nexo de causalidade e culpa, principal deles (GONÇALVES, 2008).

A responsabilidade civil objetiva entende a reparação a partir do dano causado e sua relação com a atividade que desenvolve o agente causador. Em geral, caracteriza-se pelo risco de certas atividades e pela impossibilidade de estabelecer culpa diante do dano causado. Seus elementos essenciais são: dano e nexo de causalidade, que vincula o agente ao dano, mas sem necessidade de comprovação de culpa para que resulte na obrigação de reparar o dano (GONÇALVES, 2008).

A responsabilidade civil em matéria ambiental adota a teoria da responsabilidade objetiva, conforme o art. 14, $\S 1^{\circ}$, da PNMA:

\footnotetext{
$\S 1^{\circ}$ Sem obstar a aplicação das penalidades previstas neste artigo, é o poluidor obrigado, independentemente da existência de culpa, a indenizar ou reparar os danos causados ao meio ambiente e a terceiros, afetados por sua atividade. O Ministério Público da União e dos Estados terá legitimidade para propor ação de responsabilidade civil e criminal, por danos causados ao meio ambiente (BRASIL; 1981).
}

Silva (2015, p. 216) revela que, em virtude desse dispositivo legal, deve-se comprovar apenas que: "a) houve efetivamente um dano ambiental e; b) a relação de causa e efeito entre a conduta (fato) do agente e o dano (nexo causal), para que haja responsabilização civil".

Para a questão do dano ambiental é irrelevante constatar se houve ou não imprudência ou imperícia para geração do dano, e, portanto, é "irrelevante 
a licitude ou não da atividade que causa dano ao meio ambiente", em vista do meio ambiente ser um interesse maior, da coletividade e necessário para qualidade de vida e para concretização da dignidade da pessoa humana.

Auharek e Araújo (2009, p 12) afirmam que:

O Brasil adotou em matéria de direito ambiental a teoria da responsabilidade civil objetiva, sendo assim, não é necessário à comprovação da culpa para que haja a obrigação de indenizar. A responsabilidade civil objetiva foi fundamentada na teoria do risco integral. A vinculação da responsabilidade objetiva à teoria do risco integral é a forma mais rigorosa de imputação de responsabilidade por dano ambiental, tendo em vista que, segundo essa teoria o dever de indenizar existe quando ocorre o dano, mesmo nos casos de culpa exclusiva da vítima, caso fortuito ou força maior.

Na mesma perspectiva, Baracho Júnior (2000, p. 322), aponta que vincular a responsabilidade objetiva à teoria do risco integral "expressa a grande preocupação dos doutrinadores brasileiros em estabelecer um sistema de responsabilidade o mais rigoroso possível, o que se justifica em face do alarmante quadro de degradação [...]".

Milaré (2013, p. 834) entende que a adoção da teoria do risco da atividade, que origina a teoria da responsabilidade objetiva, traz como elementos principais para que criar o dever de indenizar: "a) a prescindibilidade de investigação da culpa; b) a irrelevância da licitude da atividade; c) a inaplicação das causas de exclusão da responsabilidade civil".

Machado (2017, p. 423), menciona a necessidade de estabelecer conexão entre o prejuízo e a fonte poluidora, independente se essa fonte é múltipla ou una, podendo existir uma pluralidade de autores do dano ecológico.

Silva (2015, p. 552) aponta que há responsabilidade da "entidade ambiental que se omite na fiscalização de atividades poluidoras", utilizando-se da doutrina administrativista de responsabilização objetiva do Estado. Segue o autor afirmando que:

[...] a degradação tolerada socialmente, amparada em regular licenciamento ambiental, dentro dos padrões fixados pela legislação ambiental, não isenta o poluidor de responder civilmente pelos danos ambientais, pois a reparação não tem natureza jurídica de sanção civil, já que visa recompor o estado ambiental anterior ou compensá-lo.

Ainda que o infrator esteja licenciado para atuar economicamente, por meio de licença ambiental concedida pelo poder público, não tem o condão de afastar eventual responsabilidade civil sobre os danos que vier a causar, posto que a finalidade reparatória presta-se tão somente impor o dever de restaurar o meio ambiente lesado, bem como a sociedade afetada. 
Nesse sentido, Machado (2017, p. 434) esclarece que no caso de licença ambiental não há permissão alguma para o agente poluir ou degradar o meio ambiente:

A licença ambiental não libera o empreendedor licenciado de seu dever de reparar o dano ambiental. Essa licença, se integralmente regular, retira o caráter de ilicitude administrativa do ato, mas não afasta a responsabilidade civil de reparar. A ausência de ilicitude administrativa irá impedir a própria Administração Pública de sancionar o prejuízo ambiental; mas nem por isso haverá irresponsabilidade civil (MACHADO, 2017, p. 434).

Posicionando-se sempre a doutrina do direito ambiental que o meio ambiente é bem difuso, de uso comum do povo, com natureza própria, devendo sempre ser reparado na medida do dano causado, pois que o prejuízo fere o direito fundamental ao meio ambiente ecologicamente equilibrado, desequilibrando o direito intergeracional que garante às futuras gerações 0 usufruto do mesmo bem ambiental (SILVA, 2015, p. 578).

Para os fins a que se propõe este trabalho, o tema de responsabilidade civil em matéria ambiental se mostra relevante e urgente na medida em que os danos oriundos da falta de cuidado no transporte de água de lastro podem desencadear efeitos perversos, caracterizados por sua aparente invisibilidade e dificuldade de controle e fiscalização e, principalmente, pelo desafio de estabelecer a responsabilidade do infrator, conforme será abordado seguir.

\section{A RESPONSABILIDADE CIVIL E DANO AMBIENTAL CAUSADO POR ÁGUA DE LASTRO.}

Neste item será tratada a possibilidade da aplicação da responsabilidade civil por dano ambiental causado pelo deslastre, ou seja, pelo dano ambiental causado por despejo da água de lastro que os navios carregam de um destino a outro para garantir a estabilidade e a segurança de sua navegação.

\subsection{A Tutela Jurídica da água e da biodiversidade aquática}

Conforme mencionado anteriormente, compreende-se água de lastro como aquela utilizada a para estabilização de navios e que navegam entre os continentes, sendo despejadas em biomas diferentes (locais de destino) daqueles onde foram recolhidas originariamente.

Quando se transporta água de um lugar para outro, transporta-se 
também a biodiversidade marinha, o que torna possível a geração de danos ambientais irreversíveis ou de difícil reparação, com prejuízos não só para a fauna marinha do local que recebe as águas estranhas, mas também para a economia daquele lugar, diante de um possível desequilíbrio ecológico.

O Ministério do Meio Ambiente (MMA) afirma que biodiversidade aquática é um termo abrangente que "considera tanto um conjunto de ecossistemas aquáticos continentais, costeiros e marinhos como os seres vivos que vivem ou passam parte de seu ciclo biológico nestes ambientes" (BRASIL, 2017). São organismos vivos como "peixes, moluscos, crustáceos e algas", consideradas como "recursos pesqueiros", ou seja, são alvo da atividade pesqueira (BRASIL, 2017).

Pode-se inferir ainda, que a água, por si só, constitui um direito fundamental, finito e bem comum, dentro dos interesses difusos e coletivos já mencionados como o meio ambiente. A Lei n. 9.433/1997 que institui a Política Nacional de Recursos Hídricos (PNRH), estatui que a água é bem de domínio público, de uso comum do povo, da União, Estados ou Distrito Federal (AMADO, 2014).

A publicização das águas deu-se por sua escassez, especialmente da água doce, e sua imprescindibilidade para a continuação da vida no planeta. Conforme art. $1^{\circ}$ da PNRH: "4. A água é bem público de uso comum, motivo pelo qual é insuscetível de apropriação particular". E segue em seu item 5: "O particular tem, apenas, o direito à exploração das águas subterrâneas mediante autorização do Poder Público, cobrada a devida contraprestação" (BRASIL, 1997).

A água pode ser considerada um direito humano ou direito fundamental, haja vista sua importância para a vida no planeta. Está inserida entre os direitos de primeira dimensão a partir de uma perspectiva individual na fruição ao direito à vida sadia, bem como de terceira dimensão, sob o enfoque dos direitos difusos ao meio ambiente ecologicamente equilibrado. Disso decorre a natureza pública da proteção desse bem, vinculando a ação estatal para tal mister.

Maia Neto (2008, p. 324) explica a questão da água como direito humano:

A proteção jurídica do bem água à luz dos Direitos Humanos é urgente e muito importante através da educação e da difusão dos instrumentos internacionais ratificados pelos Estados via processos legislativos internos e externos. No contexto do Direito internacional e constitucional comparado a água deve ser considerada direito fundamental máximo, ante a necessidade imperiosa de tutela. O direito público interno e 
externo necessita de integração para a proteção da vida, da saúde e da propriedade, a existência e continuidade dos processos de vida das pessoas físicas e jurídicas - atividades e negócios - com a devida responsabilidade socioambiental.

Ainda no marco regulatório nacional, há de mencionar a tutela jurídica da água regulada no Código de Águas, editado por meio Decreto n. 24.643, de 10 de Junho de 1934, que estabeleceu a política hídrica brasileira, sendo considerado como uma das normas mais completas já produzidas sobre o tema de águas. Além deste, há também a Política Nacional de Saneamento (Lei n. 5.138/67), a Política Nacional de Irrigação (Lei n. 6.662/79), entre outras.

No plano constitucional, pode-se aferir que a proteção jurídica da água se dá a partir da análise de seus arts. $5^{\circ}, 6^{\circ}$ e 225 , os quais ostentam o status de norma fundamental, posto que tutelam o meio ambiente equilibrado, sobre o direito à vida e à saúde, estando todos intimamente ligados à imprescindibilidade da higidez dos recursos hídricos. Sendo assim, é forçoso reconhecer os atos humanos que podem afetar a qualidade de nossas águas, cujas consequências - irreversíveis ou não - colocam em perigo a fruição dos direitos supraelencados. Com isso, emerge uma preocupação voltada à gestão da água de lastro, cujo controle ou monitoramento é de difícil execução, em razão das particularidades e complexidades de rastreamento para fins de responsabilidade quando da ocorrência de danos ambientais causados pelo transporte e despejo de água de lastro, conforme será visto mais adiante.

\section{2 Água de lastro e danos ambientais}

A navegação, seja lacustre, fluvial ou marítima está presente nas atividades humanas por tempo imemoriais. Atividades de comércio, prestação de serviços, locomoção, em geral são as que se utilizam dos rios e mares, através de embarcações que ao longo do tempo, revolucionaram o desenvolvimento humano.

A água de lastro é utilizada para dar equilíbrio às navegações, sendo "recolhida no mar e armazenada em tanques nos porões dos navios, com o objetivo de dar estabilidade às embarcações quando elas estão navegando sem cargas" (BRASIL, 2017).

São águas necessárias à eficiência e segurança das embarcações. No Brasil, a legislação que trata de águas de lastro são determinadas pela NORMAM-20/DPC, Norma da Autoridade Marítima, editada em 2005 e atualizada em 2014, a qual define água de lastro como "a água com suas 
partículas suspensas levada a bordo de uma embarcação nos seus tanques de lastro, para o controle do trim, banda, calado, estabilidade ou tensões da embarcação" (BRASIL, 2005).

A água de lastro, quando de sua dispensação, promove "o de água de lastro proporciona o transporte diário de cerca de sete mil espécies entre as diferentes regiões do mundo" (GIBERTONI, 2014, p. 575).

Conforme Nascimento e Hahn (2016, p. 822-823), transferência dessas espécies:

[...] decorre de atividade inerente à operação marítima não existindo meios totalmente satisfatórios de prevenção para todos os navios e inclusive a existência ou não da água de lastro pode resultar em operações com risco de segurança ao navio e sua tripulação.

A problemática que envolve água de lastro está nas diversas espécies marinhas de um ecossistema diferente que podem trazer riscos à população marinha onde ocorre o deslastre. Conforme o Global Ballast Water Management Programme, coordenado pela International Martime Organization- IMO, a gravidade da poluição marinha através da água de lastro é suntuosa, pois que foi identificada como a quarta maior ameaça aos oceanos e à biodiversidade global mundial (IMO, 2017).

Gibertoni (2014, p. 574) afirma que o deslastre vem se tornando uma forma de contaminação cada vez mais alarmante, em virtude da dificuldade de reparação no dano ambiental causado. Nos casos de derramamento de óleo, medidas podem ser tomadas para recuperação do local afetado, no entanto, quando se trata de introdução de espécies marinhas estranhas à local, é praticamente irreversível.

O Direito Marítimo traz valores normativos que reforçam a ideia do bem ambiental difuso que são os biomas marinhos afetados pelo deslastre. Por esse motivo, há proibição da descarga de recursos hídricos de lastro em águas de jurisdição nacional, e, "embora em casos específicos seja permitida, o responsável é obrigado a reparar os danos causados ao meio ambiente e indenizar as atividades econômicas e o patrimônio público e privado" (GIBERTONI, 2014, p. 579).

Por essa razão, a NORMAM-20 (BRASIL, 2005) determina uma série de medidas para gerenciamento da água de lastro, contando com formulários para controle e fiscalização, e a constatação da irregularidade por meio de auto de infração ambiental. 


\subsection{A Responsabilidade civil por dano ambiental causado por água de lastro}

Retomando a responsabilização civil por dano ambiental, restou claro que a teoria adotada para esses temas específicos é da responsabilidade civil objetiva, que independe da culpabilidade do agente causador do dano para que se configure a obrigação de reparo.

Ibrahin (2012, p. 124) ratifica que o deslastre da água dos navios "pode acarretar diversos danos que devem ser evitados pelos agentes envolvidos no sistema de gerenciamento de água de lastro, os quais devem ser fiscalizados pelo poder público".

Tanto o poder público tem seu dever de fiscalizar, quanto as embarcações devem adotar medidas preventivas. São documentações necessárias para controle que devem ser informadas às autoridades.

Toda a atividade portuária deve atuar de forma preventiva em todos os procedimentos atinentes à água de lastro, a fim de se evitar impactos ambientais. Os "custos sociais" e a "internalização dos custos" da atividade portuária devem ser suportados por todos os envolvidos no processo marítimo. O conjunto de normas que disciplinam o deslastre da água dos navios implica na necessidade de responsabilizar o proprietário do navio, o armador ou operador, o comandante, a pessoa física ou jurídica de direito público ou privado, que legalmente represente o porto organizado, a instalação portuária, a plataforma e suas instalações de apoio e o proprietário da carga, os quais, por suas ações ou omissões ocasionem danos ao meio ambiente (IBRAHIN, 2012, p. 124).

A responsabilidade pela prática de quaisquer atos nocivos ao meio ambiente por parte dos operadores dos sistemas marítimos, especialmente quanto ao deslastre de água irregular foi acolhida pela teoria do risco, imputando a todos que "criarem um risco de dano a terceiros e ao meio ambiente, no exercício de sua atividade, a responsabilidade solidária objetiva própria, mesmo que seu comportamento seja isento de culpa" (IBRAHIN, 2012, p. 127).

Gibertoni (2014, p. 45) acrescenta:

A responsabilidade vai além da reparação do dano ambiental. A legislação nacional determina que da entidade exploradora de porto organizado, do proprietário ou operador de plataforma ou de navio, pela descarga de material poluente em águas sob jurisdição nacional, são obrigados a ressarcir as despesas efetuadas pelos órgãos competentes para o controle ou minimização da poluição causada, independentemente de prévia autorização e de pagamento de multa. 
A divisão de responsabilidades do comandante e do armador, patrão, reputa-se irrelevante, visto que, na maioria das vezes, "ajuizar uma ação em face do armador revelou-se mais conveniente do que em face do comandante, pessoa física”. O proprietário do navio, por ser titular da propriedade da embarcação e utilizá-la para atividades comerciais, é implicado na hipótese de responsabilidade, tanto objetiva quanto solidária (IBRAHIN, 2012, p. 127).

No âmbito do poder legislativo, há de se fazer referência a duas iniciativas que almejaram regular a questão da responsabilidade civil por danos causados por deslastre, a saber: o Projeto de Lei n. 5.263, de 2005, apresentado pelo Deputado Feu Rosa, do Espírito Santo, e o Projeto de Lei n. 6.260, de 2005, proposto pelo Deputado Carlos Willian em 24 de novembro de 2005. Atualmente, tais projetos encontram-se arquivados desde janeiro de 2007. Ambos visavam determinar princípios básicos para a atividade que resulta em deslastre, no entanto, foram alvos de críticas contundentes no que se refere à inviabilidade técnica e jurídica de sua implantação (IBRAHIN, 2012, p. 129).

Considerando que o dano ambiental promovido pelo deslastre fere não somente os princípios do direito ambiental da precaução e da prevenção, mas também do poluidor-pagador. A responsabilidade civil para casos como os já abordados anteriormente deve ser aplicada como urgente e relevante. Nesse mesmo sentido, Silva (2005) afirma que a responsabilidade civil ambiental não se trata de uma mera relação inter partes individuais, já que qualquer ameaça ao meio ambiente, bem comum, interesse difuso e coletivo, implica também ameaça à qualidade de vida no planeta. Portando, trata-se de uma questão de dever ético, aliada ao princípio da precaução", em virtude dos riscos presentes na sociedade contemporânea (SILVA, 2005).

Com efeito, analisando os pressupostos da responsabilidade civil em matéria ambiental e os desafios de sua aplicação, o presente estudo manifesta-se no sentido de que as prescrições jurídicas voltada à proteção ambiental estejam mais abertas à absorção das informações técnicas a respeito desse tipo de dano, para que possa cumprir seu objetivo na garantia da integridade dos recursos hídricos. É necessário, portanto, o rigor das medidas de prevenção de danos decorrentes do transporte precário de água de lastro, com monitoramento e fiscalização constantes e eficazes, sob pena de estarmos vulneráveis e constantemente dependentes de ações reparatórias que nem sempre logram a restauração da qualidade das nossas águas. 


\section{CONCLUSÃO}

Este trabalho estudou a análise jurídica da responsabilidade civil por dano ambiental causado por água de lastro. Essas águas navegam nos porões dos navios pelos continentes afora, com intuito de oferecer estabilidade e segurança às embarcações, quando estas navegam sem carga.

Quando são descarregadas sem a devida perícia e precaução, podem gerar danos ambientais irreversíveis, visto que, juntamente com a água, vem a biodiversidade aquática externa e muitas vezes nociva à biota marinha da localidade onde vai ser descarregada.

De danos ambientais a danos econômicos, o deslastre deve ser controlado, gerenciado e fiscalizado para que se cumpram as normativas relacionadas. O não cumprimento, geraria responsabilidade civil aos responsáveis, independente do dolo ou culpa, pois que a teoria da responsabilidade civil adotada para dano ambiental é a teoria da responsabilidade objetiva, que apenas imprescinde do fato danoso e o nexo causal capaz de estabelecer o liame entre a conduta ilícita e a degradação que lhe é imputada.

Da leitura deste texto, foi possível compreender que a responsabilidade civil é um instrumento cujo objetivo consiste em impelir os agentes de comportamentos danosos a arcar com o risco integral da atividade que executam. Em razão disso, reforça-se a possibilidade de tornar viável a responsabilização civil sobre o deslastre, impondo-se o dever de reparação ao agente que concorreu direta ou indiretamente para a degradação ecológica verificada, pela via da solidariedade. E, nessa cadeia de comprometimento pela proteção ambiental, estaria ainda o Estado apto a responder quando negligencia suas funções de controle, gerenciamento e fiscalização do deslastre.

Verificou-se que o dano causado por transporte irregular por água de lastro muitas vezes ocorre de forma silenciosa e invisível aos olhos do Poder Público, que nem sempre se manifesta de forma instantânea, e tais fatos concorrem para facilitar a defesa do poluidor, conferindo-lhe diversos subterfúgios dado pela legislação que aproveita àquele cuja culpa não foi satisfatoriamente comprovada por insuficiência probatória, para estabelecer o nexo de causalidade entre sua conduta e a lesão por ele causada, impondo-se, assim, a necessidade de uma aplicação rigorosa das normas em vigor, bem como uma formulação de outras que sejam capazes de efetivar a reparabilidade civil sobre o deslastre.

Sendo assim, cabe a adoção de diversas medidas de caráter preventivo 
e reparatório, de modo que os dispositivos legais possam absorver maior rigor para serem aplicados de forma eficaz quando da ocorrência desse tipo de dano. No âmbito da prevenção (sentido lato), é imperioso uma maior difusão de informações acerca dos riscos e consequência da lesão aos nossos recursos hídricos, concretizando, assim, o princípio da educação ambiental, e formando uma ecocidadania voltada à fiscalização difusa da biota aquática, conduzindo a sociedade à construção de um ethos de responsabilidade ambiental compartilhada.

\section{REFERÊNCIAS}

ALEXY, R. Teoria dos direitos fundamentais. São Paulo: Malheiros, 2008. AMADO, F. Direito Ambiental esquematizado. 5. ed. Rio de Janeiro: Forense, 2014.

ANTUNES, P. B. Direito Ambiental. 8. ed. Rio de Janeiro: Lumen Juris, 2010.

AUHAREK; Z. A.; ARAÚJO, M. M. A responsabilidade civil pelo dano ambiental. Belo Horizonte: PUC-Minas, 2009. Disponível em: http:// www.fmd.pucminas.br/Virtuajus/1_2009/Discentes/A\%20Responsabilidade $\% 20$ Civil $\% 20$ pelo\%20dano\%20Ambiental.pdf. Acesso em: 2 jul. 2019.

BARACHO JÚNIOR, J. A. O. Responsabilidade civil por dano ao meio ambiente. Belo Horizonte: Del Rey, 2000.

BRASIL. Lei $n$. 6.938, de 31 de agosto de 1981. Dispõe sobre a Política Nacional do Meio Ambiente, seus fins e mecanismos de formulação e aplicação, e dá outras providências. Brasília, DF: Presidência da República.

BRASIL. [Constituição (1988)]. Constituição da República Federativa Brasileira. Brasília, DF: Assembleia Nacional Constituinte, 1988.

BRASIL. Lei n. 8.078, de 11 de setembro de 1990. Institui o Código de Defesa do Consumidor. Brasília, DF: Presidência da República, 1990.

BRASIL. Lei $n$. 9.433, de 8 de janeiro de 1997. Institui a Política Nacional de Recursos Hídricos, cria o Sistema Nacional de Gerenciamento de Recursos Hídricos, regulamenta o inciso XIX do art. 21 da Constituição Federal, e altera o art. $1^{\circ}$ da Lei n. 8.001, de 13 de março de 1990, que modificou a Lei n. 7.990, de 28 de dezembro de 1989. Brasília, DF: Presidência da República, 1997. 
BRASIL. Lei n. 10.406, de 10 de janeiro de 2002. Institui o Código Civil. Brasília, DF: Presidência da República, 2002.

BRASIL. Ministério do Meio Ambiente. Agenda 21 brasileira: resultados da consulta nacional. 2. ed. Brasília, DF: MMA, 2004.

BRASIL. Marinha do Brasil. NORMAM-20/DPC, de 14 de junho de 2005. Norma da autoridade marítima para o gerenciamento da água de lastro de navios da diretoria de portos e costas. Disponível em: https://www.dpc. mar.mil.br/normam/N_20/Introducao.pdf. Acesso em: 13 jul. 2019.

BRASIL. Ministério do Meio Ambiente. Secretaria de Biodiversidade. Biodiversidade aquática. Disponível em: http://www.mma.gov.br/biodiversidade/biodiversidade-aquatica. Acesso em: 1 nov. 2017.

BRASIL. Ministério do Meio Ambiente. Água de Lastro. Disponível em: http://www.portodesantos.com.br/acoesCampanhas.php?pagina=02. Acesso em: 2 jul. 2019.

BRUNDTLAND, G. H. (Org.). Nosso futuro comum. Rio de Janeiro: FGV, 1987.

CARNEIRO, R. Direito Ambiental: uma abordagem econômica. Rio de Janeiro: Forense, 2009.

CARVALHO, D. W. Dano Ambiental futuro: a responsabilização civil pelo risco ambiental. 2. ed. rev. atual. e ampl. Porto Alegre: Livraria do Advogado, 2013.

DERANI, C. Direito Ambiental Econômico. 3. ed. São Paulo: Saraiva, 2008.

GIBERTONI, C. A. C. Teoria e prática do direito marítimo. Rio de Janeiro: Renovar, 2014.

GONÇALVES, C. S. R. Responsabilidade civil. 10. ed. São Paulo: Saraiva, 2008.

IBRAHIN, F. J. Gerenciamento e controle da água de lastro e a responsabilidade civil dos operadores do sistema. Dissertação (Mestrado) - Programa de Pós-Graduação em Direito Ambiental e Políticas Públicas, Universidade Federal do Amapá, Macapá, 2012.

IMO - INTERNATIONAL MARITIME ORGANIZATION. Building partnerships to assist developing countries to reduce the transfer of harmful 
aquatic organisms in ships' ballast water: The GloBallast Partnerships Project 2007-2016. London: IMO, 2017. Disponível em: http://globallast. imo.org/. Acesso em: 24 jul. 2019.

LEFF, E. Epistemologia ambiental. 3 ed. São Paulo: Cortez, 2002.

MACHADO, P. A. L. Direito Ambiental Brasileiro. São Paulo: Malheiros, 2017.

MAIA NETO, C. F. Água: direito humano fundamental máximo. Proteção jurídica ambiental, responsabilidade pública e dever da cidadania. Verba Juris, João Pessoa, ano 7, n. 7, jan./dez. 2008.

MAMED, D. O.; DUARTE, F. C. Meio ambiente e sustentabilidade no Mercosul: subsídios para uma harmonização legislativa das normas ambientais dos países-membros. In: XXI ENCONTRO NACIONAL DO CONPEDI: SISTEMA JURÍDICO E DIREITOS FUNDAMENTAIS INDIVIDUAIS E COLETIVOS, 21., 2012, Uberlândia. Anais [...]. Florianópolis: Fundação Boiteux, 2012. p. 5289-5306.

MILARÉ, E. Direito do Ambiente: doutrina, prática, jurisprudência e glossário. São Paulo: Revista dos Tribunais, 2013.

MILARÉ, É. Direito do Ambiente: a gestão ambiental em foco. 7. ed. São Paulo: Revista dos Tribunais, 2011.

MORATO LEITE, J. R.; BELCHIOR, G. Estado de Direito Ambiental: uma análise da recente jurisprudência ambiental do STJ sob o enfoque da hermenêutica jurídica. Revista de Direito Ambiental, São Paulo, v. 56, out./ dez. 2009.

NASCIMENTO, E. P. Trajetória da sustentabilidade: do ambiental ao social, do social ao econômico. Estudos Avançados, São Paulo, v. 26, n. 74, São Paulo, p. 51-64, 2012.

NASCIMENTO, C. B.; HAHN, E. Responsabilidade Civil decorrente de dano ambiental causado por dispensação da água de lastro, na costa brasileira. Revista Eletrônica Direito e Política, Itajaí, v. 11, n. 2, p. 817-847, 2016.

ONU - ORGANIZAÇÃO DAS NAÇÕES UNIDAS. Declaração de Estocolmo. Estocolmo: ONU, 1972.

ONU - ORGANIZAÇÃO DAS NAÇÕES UNIDAS. Declaração do Rio. 
Rio de Janeiro: ONU, 1992.

SILVA, R. F. T. Manual de Direito Ambiental. 5. ed. Salvador: Jus Podium, 2015.

SILVA, S. T. Responsabilidade civil ambiental. In: PHILLIPPI JR, A.; ALVES, A. C. Curso interdisciplinar de Direito Ambiental. Barueri: Manole, 2005. p. 425-46.

Artigo recebido em: 14/08/2019. Artigo aceito em: 30/03/2020.

\section{Como citar este artigo (ABNT):}

NOGUEIRA, C. B. C.; LIMA, C. C.; ALMEIDA, R. L. P. A responsabilidade civil quanto ao dano ambiental por água de lastro. Veredas do Direito, Belo Horizonte, v. 17, n. 37, p. 347-373, jan.-abr. 2020. Disponível em: http://revista.domhelder.edu.br/index.php/veredas/article/view/1627. Acesso em: dia mês. ano. 